\title{
Craniodental Characters in the Taxonomy of Propithecus
}

\author{
Colin P. Groves • Kristofer M. Helgen
}

Received: 23 August 2006 / Accepted: 1 November 2006 /

Published online: 6 December 2007

(C) Springer Science + Business Media, LLC 2007

\begin{abstract}
The indriid genus Propithecus comprises the sifakas, medium-sized lemurs endemic to the forests of Madagascar. Traditionally, scientists divided the genus into only 2 or 3 species - Propithecus diadema, P. verreauxi, and, since 1988, $P$. tattersalli - with 4 or 5 subspecies in each of the first 2 taxa, but recent authors have suggested that many more distinct species should be recognized. We draw from quantitative and qualitative studies of craniodental traits to evaluate further the phenetic distinctiveness and taxonomic status of each named form of Propithecus. We recognize 9-10 species in the genus. The 4 or 5 species of the Propithecus diadema group -P. diadema, P. candidus, P. perrieri, P. edwardsi, and perhaps P. holomelas, if distinct - share several derived features, including large average body size and a mandible specialized for rotational chewing, and clearly comprise a closely related complex. The 5 species of the Propithecus verreauxi group $-P$. verreauxi, $P$. coquereli, $P$. deckenii, $P$. coronatus, $P$. tattersalli - are each highly distinctive morphologically and likely do not comprise a monophyletic group. In particular, we point out the highly distinctive cranial features of Propithecus coronatus, which researchers have traditionally largely overlooked.
\end{abstract}

Keywords craniodental $\cdot$ Madagascar $\cdot$ Propithecus $\cdot$ species $\cdot$ taxonomy

C. P. Groves $(\bowtie)$

School of Archaeology and Anthropology, Australian National University,

Canberra ACT 0200, Australia

e-mail: colin.groves@anu.edu.au

K. M. Helgen

Division of Mammals, National Museum of Natural History, Smithsonian Institution,

Washington, D.C. 20013, USA 


\section{Introduction}

The species of Propithecus (to 2004)

Until the 1980s, the standard classification of sifakas (Propithecus) delineated 2 species, Propithecus diadema (from the eastern rain forests of Madagascar) and $P$. verreauxi (from the dry forests of the west and south). The arrangement dates ultimately from Schwarz (1931), who diagnosed the 2 species and recognized subspecies within each as follows (distributions mostly cited from Milne-Edwards and Grandidier):

Propithecus diadema Bennett, 1832. Size larger. Tail not projecting beyond heel. Fur loose.

- Propithecus diadema candidus Grandidier, 1871. Synonym: Propithecus sericeus Grandidier, 1872. General color white, the head only occasionally gray. "The north-eastern coast ranges of the island from the region of Bemarivo (14 $\left.16^{\prime} 30^{\prime \prime} \mathrm{S}\right)$ ... to the Bay of Antongil" (1931:422)

- Propithecus diadema diadema Bennett, 1832. Synonyms: Macromerus typicus A. Smith, 1833, Indris albus Vinson, 1862. General color gray. Head blackish, limbs yellow. "...from the Bay of Antongil as far south as the Masora River, south of Maganoro (about 20S)" (1931:422)

- Propithecus diadema edwardsi Grandidier, 1871. Synonym Propithecus bicolor Gray, 1872. Prevailing color black or brownish black. Lower back creamy; pygal triangle dark brown. "....along the south-east coast between the Masora $\left(20^{\circ} \mathrm{S}\right)$ and Matitana Rivers (about 22 ${ }^{\circ} \mathrm{S}$ )" (1931:422).

- Propithecu diadema holomelas Günther, 1875. Upper surface entirely black. Pygal triangle reddish brown. "The range of this race appears to be the inland mountain range in the southeast of Madagascar, whereas $P$. $d$. edwardsi inhabits the coast range" (1931:423)

Propithecus verreauxi Grandidier, 1867. Size smaller. Tail projecting beyond heel. Fur not loose.

- Propithecus verreauxi deckenii Peters, 1870. All white. “...found only between the Rivers Mahavavy (Manzaray) and Mananbolo" (1931:424).

- Propithecus verreauxi coquereli (Grandidier, 1867). Synonym Propithecus damonis Gray, 1870. Inside of limbs chestnut-brown. Lower side tinged with rufous. "...the range is delimited by the river Antamba (Loza), Bay of Narenday, in the north, and the River Betsiboka in the south" (1931:423).

- Propithecus verreauxi coronatus A. Milne-Edwards, 1871. Synonym Propithecus damanus Schlegel, 1876. Crown of head black or blackish brown. Limbs white. Back at most tinged with pearl-gray. Lower surface, at least breast, rusty red. Nasals very broad. "...between the Besiboka [sic] and Mahavavy Rivers" (1931:423).

- Propithecus verreauxi verreauxi Grandidier, 1867. As in coronatus but lower surface white. Nasals small. "...from the Tsidsobon River on the west coast to the region of Ft. Dauphin in the south-east" (1931;424).

- Propithecus verreauxi majori Rothschild, 1894. Crown of head black or blackish brown. Inside of limbs and greater part of back chocolate-brown. Known only 
from “"Antinosy' (=Antanosy)... The specimens of true verreauxi collected by Last and also labeled 'Antinosy country' are probably from the plains further west, and collected on the way to or from Tuléar, on the S.W. coast" (1931:424).

The original describers had ranked all these subspecies as full species, and Schlegel (1876) arranged them into 2 specific groups but subsequent authors variously listed them as species, subspecies, or mere varieties until Schwarz (1931) formalized their arrangement.

Lavauden (1931) described a further species, the all-black Propithecus perrieri from Analamera; writing at approximately the same time as Schwarz, he had not seen Schwarz's (1931) paper reducing the number of species, and it remained for Osman Hill (1953) to fit Propithecus perrieri into the 2-species model as a subspecies of Propithecus diadema. The species and subspecies arrangement of Propithecus was thenceforth more or less stabilized for nearly $30 \mathrm{yr}$.

Tattersall (1982) described what he interpreted, with misgivings, as a variant of Propithecus diadema candidus, which he had found in 1974 in dry forest near Daraina, $30 \mathrm{~km}$ northwest of Vohémar in the northeast of Madagascar, not far south of Analamera. Though white like Propithecus diadema candidus, they differed in having a bright orange patch between the ears, which were not hidden by fur. Later, Simons (1988) captured specimens alive and described them as a new species, Propithecus tattersalli, with a mosaic of character states resembling those of various other taxa, i.e., the karyotype and a short tail more resembling Propithecus diadema, vocalizations are more like those of $P$. verreauxi verreauxi than of either $P$. diadema or $P$. verreauxi coquereli, as well as unique features. Groves (2001) placed Propithecus tattersalli in the $P$. diadema species-group; the only serious demurral has been by Pastorini et al. (2001), who regarded it as only subspecifically distinct, if that, from P. verreauxi coquereli.

Rumpler and Albignac (1979) karyotyped several taxa of Propithecus. Propithecus verreauxi verreauxi, $P$. v. deckenii, $P$. v. coronatus, and $P$. v. coquereli all had the same karyotype: $2 n=48, F N=76$, with 6 metacentric (M), 8 submetacentric (SM), and 9 acrocentric (A) autosomal pairs (though 1 small pair may be either A or M), the $\mathrm{X}$ a medium-sized S, the Y a small A. Poorman (1983), however, interpreted the autosomes of Propithecus verreauxi coquereli as 10 M, 5 SM, and 8 A. Propithecus diadema diadema and $P$. $d$. perrieri both had $2 n=42, \mathrm{FN}=72$, with $7 \mathrm{M}, 8 \mathrm{~S}$, and $5 \mathrm{~A}$ autosomal pairs (again, one small pair could be $\mathrm{A}$ or $\mathrm{M}$ ), the $\mathrm{X}$ a medium-sized $\mathrm{S}$ and the $\mathrm{Y}$ a tiny A. Later, however, Rumpler et al. (1988) studied a female Propithecus diadema edwardsi and reported $2 n=44$, with $16 \mathrm{M}$ or S and $5 \mathrm{~A}$ (the X again a medium-sized S), the difference being accounted for by an extra pair of microchromosomes. Rumpler et al. (1988) could not decide whether the difference from the other presumed subspecies of Propithecus diadema was real or whether the presence of the extra pair was undetected in Rumpler and Albignac's (1979) earlier study. Recently, however, Mayor et al. (2004) confirmed that it is a genuine difference, and that the last remaining taxon of the group, Propithecus diadema candidus, has $2 n=42$ (Rumpler et al. 2004). The karyotype of female Propithecus tattersalli is $2 n=42$, with $11 \mathrm{M}, 6 \mathrm{~S}$, and 4 A pairs, among which the X could not be identified; one of the acrocentrics is medium-sized, and there are nucleolar organizing regions on 2 chromosomes versus only 1 in both Propithecus diadema edwardsi and Propithecus verreauxi coquereli (Simons 1988). 
Most recently Mayor et al. (2004) published a wide-ranging study drawing from mitochondrial D-loop sequence data, karyotypes, and external morphometrics of living individuals, including all recognized taxa with the exception of Propithecus deckenii and P. coronatus. Each of them proved, via the population aggregate analysis method of Davis and Nixon (1992), to be a diagnosable entity under the Phylogenetic Species Concept (PSC), and they accordingly proposed to accord each of them specific rank.

As a footnote, most of the taxa in the genus have differently colored eyes (Garbutt 1999), and the tally of taxa is apparently not yet complete: $c f$. the story of Juliet, a sifaka from the Tsinjoarivo area (Anon 1999). This sifaka population apparently may represent a new species, to which the nomen nudum Propithecus marshi has been applied (http://www.naturalworldtours.co.uk/articles2001/march/march0301a.htm).

Taxa in the Propithecus diadema group

Lavauden (1931) noted that his new species, Propithecus perrieri, is entirely black like $P$. holomelas — which he still recognized as a species - but he considered it to be actually closer to the small, western species $P$. coquereli because the ears are small and glabrous, the eyes are brown with bottle-green reflections, and the head and body are only $500 \mathrm{~mm}$ in length, the tail $450 \mathrm{~mm}$. Though he stated that the type would be placed in the collections of the Muséum National d'Histoire Naturelle, Paris (an assertion echoed by Petter et al. 1977), the type series is actually at the Museum of Comparative Zoology at Harvard (Helgen 2002). Allen (1939) cavalierly placed Propithecus perrieri in the synonymy of $P$. verreauxi coquereli, merely stating that it was "probably a melanistic individual." We are not sure who reversed Allen's action, probably Osman Hill (1953); when he did so, however, he listed it as a subspecies of Propithecus diadema, thereby creating another precedent that most subsequent authors regarded as set in stone. Groves (2001) restored Propithecus perrieri to full specific rank.

The taxonomic status of the other black sifaka suffered a different fate. Petter et al. (1977) argued that Propithecus diadema holomelas represents an extreme melanistic morph of $P$. diadema edwardsi, which shows a great deal of variation in the degree of extension of the chocolate brown on the flanks and mid-back. Tattersall (1982), in contrast, at first tended to believe in the existence of Propithecus diadema holomelas, with a restricted range near Fianarantsoa; though the area is close to the distribution of Propithecus diadema edwardsi there did not, he thought, seem to be any intermediates in terms of pelage pattern. Later Tattersall (1986) determined that the type locality of Propithecus diadema holomelas, Nandihizana, lies within the range of $P$. $d$. edwardsi and that, according to one 19th century observer, both taxa occurred there. Accordingly, he confidently synonymized Propithecus diadema holomelas with $P$. d. edwardsi. Groves (2001) also recognized Propithecus edwardsi as a full species, with $P$. holomelas as a synonym.

Propithecus diadema edwardsi differs in its karyotype from other members of the diadema species-group (Rumpler and Albignac 1979; Rumpler et al. 1988; Mayor et al. 2004). The various members of the group differ also in external body proportions and in D-loop sequences (Mayor et al. 2004). There is also a possibility that taxa within Propithecus diadema differ in the histology of the male throat gland; 
after describing differences between the male throat glands of $P$. $d$. candidus and 3 members of the verreauxi group (verreauxi, deckeni, and coquereli), Rumpler and Andriamiandra (1971:440) revealed that they examined "un couple de P. diadema diadema dont le mâle possède une glande de cou qui a la même structure histologique que celle des P. verreauxi verreauxi étudiés." Groves (2001), in retaining candidus as a subspecies of Propithecus diadema, was unaware of the endnote.

\section{Taxa in the Propithecus verreauxi group}

Petter et al. (1977) discussed skull differences that distinguish Propithecus verreauxi coronatus and $P$. v. deckenii from other forms of $P$. verreauxi -including a boss on the nasal bones, giving a characteristic form to the head in living individuals - but considered it preferable to retain them in the same species. They commented extensively on color variation within Schwarz's subspecies Propithecus verreauxi verreauxi; in particular, they argued that Propithecus verreauxi majori is just a melanistic morph occurring within the range of $P$. v. verreauxi, noting that they can occur together in the same troop. It was on this basis that Tattersall (1982) accepted the synonymy of Propithecus verreauxi majori with P. v. verreauxi.

On the basis of field observations, Kaudern (1915) mapped Propithecus verreauxi deckenii and $P$. v. coronatus as allopatric taxa separated completely by the Mahavavy River in northwestern Madagascar. Tattersall (1982), however, reported Propithecus verreauxi deckenii at Katsepy lighthouse, well to the east of the Mahavavy, i.e., on the same side as P. v. coronatus. Later, Tattersall (1986) reiterated the sighting of Propithecus verreauxi deckenii at Katsepy, and noted that he and Robert Sussman had sighted P. v. coronatus at Ambararatabé, to the west of the Mahavavy (the side of $P$. v. deckenii). Nevertheless he felt that their ranges were probably still distinct as a whole, and that they should not be synonymized. 2 yr later, however, in a personal communication to Simons (1988), he concluded that they were mere color variants, and should be synonymized. Likewise, Pastorini et al. (2001) could not resolve distinct mtDNA clades for the 2 taxa and proposed to unite them (and probably Propithecus verreauxi verreauxi as well) into a single subspecies. In deference to Tattersall's findings, but disputing his interpretation of them as reported by Simons (1988), Groves (2001) retained Propithecus verreauxi coronatus as a subspecies of Propithecus deckenii in his classification of the Propithecus verreauxi group.

Curtis et al. (1998), however, surveyed the region on either side of the lower Mahavavy, and could find no trace of anything but Propithecus verreauxi deckeni to the west of it (including a melanistic variant, common in the Analabe region) or P. $v$. coronatus to its east. Accordingly, they strongly disputed Tattersall's conclusion that they are simply color variants. Further, Thalmann et al. (2002) reviewed the data and found that there is very little overlap between the forms living on either side of the river; the melanistics of Curtis et al. (1998) and a report of coronatus-like individuals at Kasijy (100 km upstream of Analabe) are, they argued, be best interpreted as cases of the Mahavavy locally changing course and passively transferring small populations of Propithecus coronatus to the left bank, permitting some interbreeding. Moreover, they found that Propithecus verreauxi deckenii does not now appear to occur at Katsepy lighthouse, though this does not necessarily affect an interpretation of the taxonomy. They concluded that not only are Propithecus 
verreauxi deckenii and $P$. v. coronatus taxonomically distinct, but that they qualify under the Phylogenetic Species Concept (PSC) as distinct species.

\section{Aims of the Present Study}

Several authors have mentioned skull differences among taxa of Propithecus. Groves (2001) summarized the evidence, and reported mostly impressionistic original observations on skulls, but he provided no metrical datum. Schwarz (1931) and Petter et al. (1977) also mentioned cranial characters that appeared to distinguish some of the taxa, in particular Propithecus coronatus and P. deckenii. We assessed the claimed differences to see if they can be represented metrically.

\section{Materials and Methods}

Groves examined skulls of Propithecus in Naturalis (the Rijksmuseum van Natuurlijk Historie), Leiden (RMNH), and devised a set of measurements to distinguish between the $P$. diadema and $P$. verreauxi groups, and between taxa within them. Helgen examined and measured skulls in the Museum of Comparative Zoology, Harvard (MCZ) and the Field Museum of Natural History, Chicago (FMNH), and a few selected skulls, including types, in the Natural History Museum, London (BMNH); the Zoologisches Museum Alexander Humboldt, Berlin (ZMB); and the American Museum of Natural History, New York (AMNH). The patterns of the associated skins were consistent with the stated taxonomic designations, and localities fell within known distributions of the sample taxa, so the correct identification of the skulls is not in doubt. We added measurements of additional skulls by Kaudern (1915).

We measured only skulls in which all molars were erupted. We divided them into 4 age categories, as follows:

Young adult (ya) Kaudern (1915) stage I: basilar suture (=spheno-occipital synchondrosis) widely open; no visible wear on third molars

Young-adult-to-adult Kaudern stage II: basilar suture in process of closing; minimal (y/ad)

Adult (ad)

Old wear on third molars

Kaudern stage III: basilar suture closed; third molars with noticeable wear

Kaudern stage IV: basilar suture closed, and with strong wear on third molars

We took the following measurements:

Gtl: Greatest skull length

$\mathrm{Cbl}$ : Condylobasal length

Biorb: Biorbital breadth

Bican: Bicanine breadth (greatest breadth of rostrum)

Mandibular condyle breadth, bilateral

Mandibular condyle breadth, anteroposterior

望 Springer 
Maxillary toothrow length (premolars plus molars)

For the Propithecus diadema group, we took the following additional measurements:

$\mathrm{M}^{2}$ breadth

$\mathrm{M}^{3}$ breadth

Mandibular toothrow length (premolars plus molars)

$\mathrm{P}_{4}$ length

$\mathrm{P}_{4}$ breadth

Mandibular molar row length

For the Propithecus verreauxi group, we took the following additional measurements:

Brainht Braincase height (from basioccipital plane to vertex of cranial vault)

Inht Interorbital height (from palatal plane to vertex of interorbital pillar)

Nasht Nasal height (vertical height of nasal bones above $\mathrm{P}^{3}$ )

Distance between temporal lines where they curve medially behind orbits

Minimum distance between temporal lines (towards back of vault)

We did not take all measurements on all individuals. We entered the measurements into a data file (SPSS.11 for Windows) and ran a series of univariate, bivariate, and multivariate (Discriminant Function) analyses, genus-wide and within species groups.

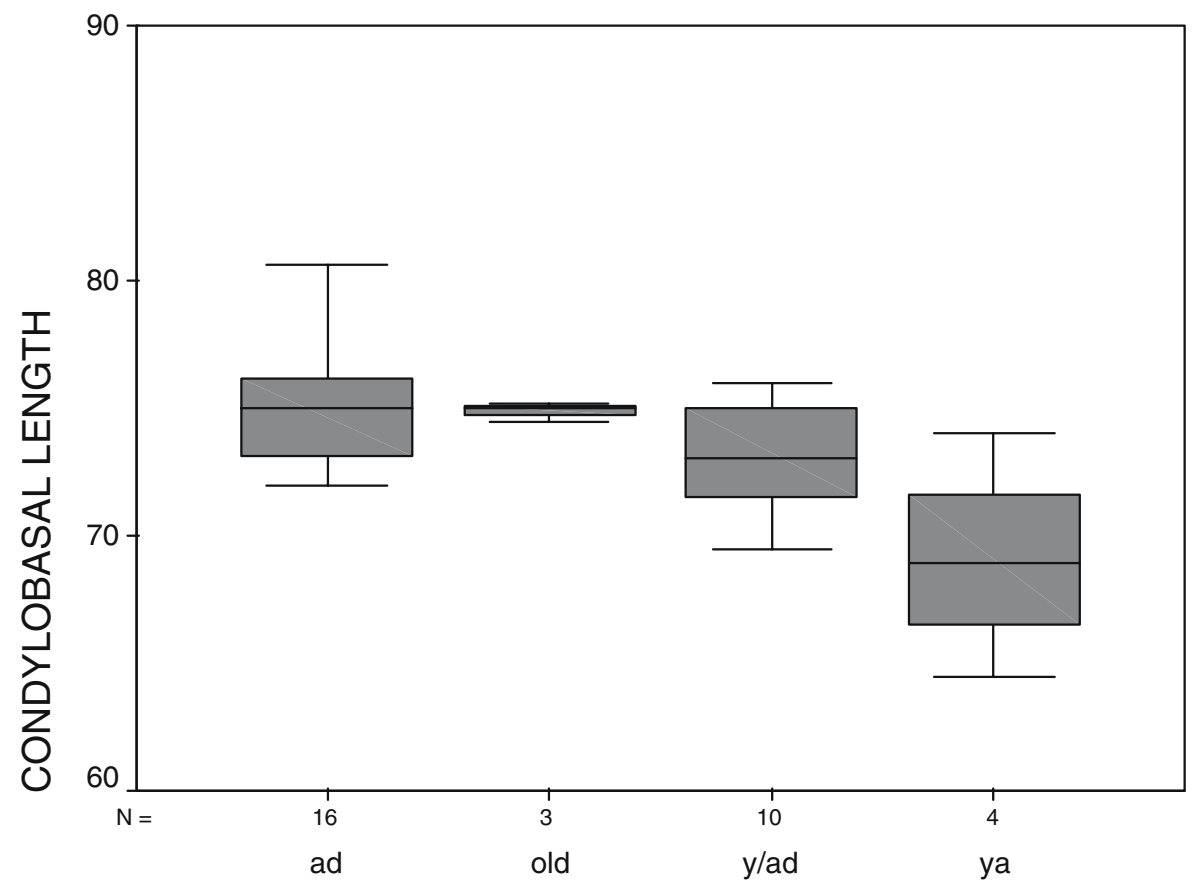

AGE

Fig. 1 Boxplots of skull size (condylobasal length) for different age groups of Propithecus coquereli. Medians, quartiles, and observed ranges are depicted. 


\section{Results}

Sex and Age Differences

Like Kaudern (1915), we found no sexual dimorphism of any kind in skull measurements, so we combined the sexes in all analyses.

In the largest sample, that of Propithecus coquereli, there is a strong increase in skull size, as represented by condylobasal length, between young adults and the young-adult-to-adult stage, and a further, but less marked, increase to adults but, as expected, no further increase from adult to old specimens (Fig. 1). The next largest sample —Propithecus diadema (sensu stricto) - appeared to indicate the same relationships. Therefore we combined adult and old categories, but felt it unwise to combine other age categories with adults for univariate analyses.

\section{Relationships Between Species-Groups of Propithecus}

In the dry forest sifakas (predominately the Propithecus verreauxi group), the auditory bullae and external auditory meatus tend to be larger than in the rain forest group (the Propithecus diadema group). These are average differences, and are difficult to measure. The taxa of the Propithecus diadema group tend to be larger overall, though with wide overlap, but the basicranium is less elongate, the rostrum tends to be wider and more rounded, and the dental arcade to diverge less posteriorly.

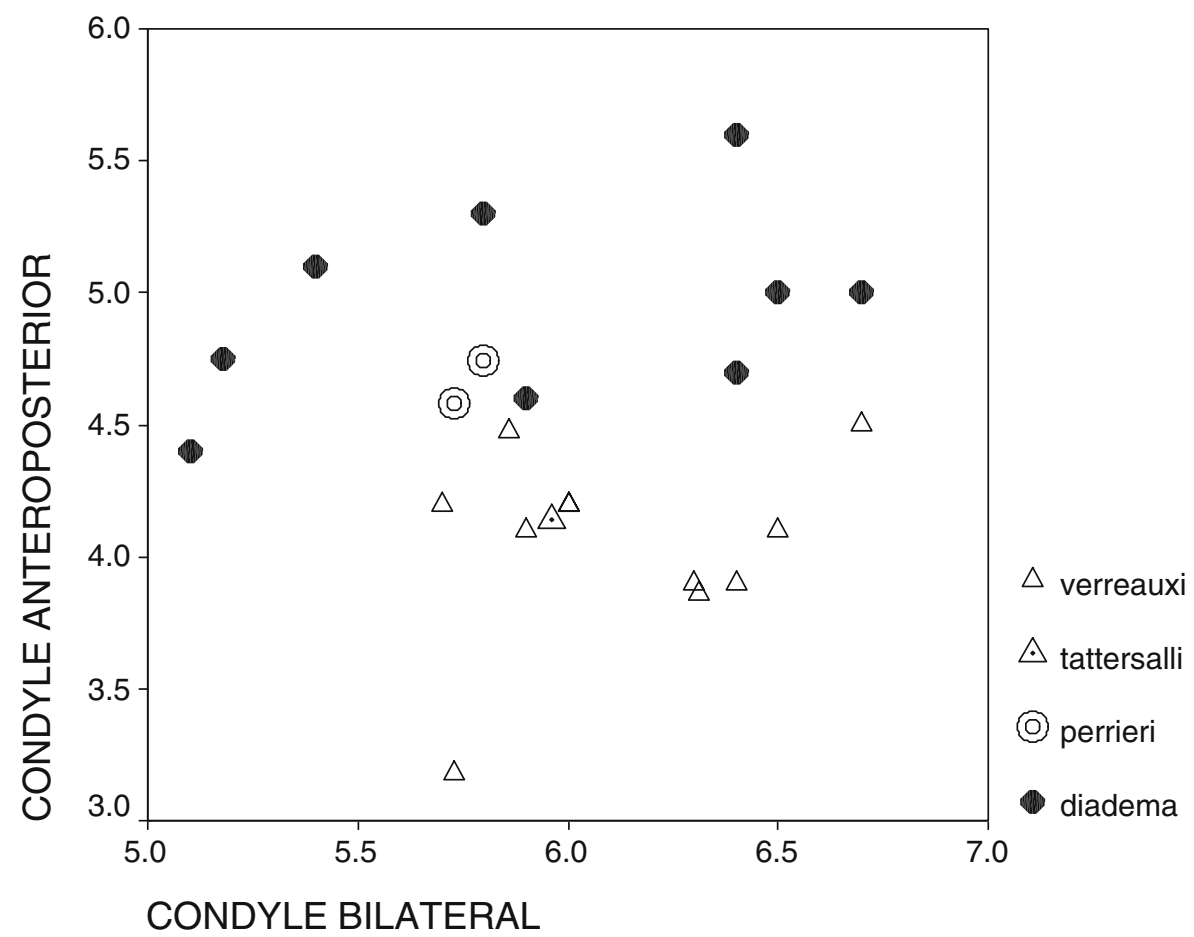

Fig. 2 Shape of mandibular condyle in the 2 species-groups of Propithecus.

Springer 
The most clear-cut difference between the 2 species-groups lies in the shape of the mandibular condyle, which is anteroposteriorly narrower and transversely widened in Propithecus verreauxi group (including $P$. tattersalli), and more rounded (the 2 diameters more nearly equal) in the $P$. diadema group, including $P$. perrieri (Fig. 2). Presumably this relates to masticatory function, suggesting a more rotary chewing pattern in the Propithecus diadema group.

On analysis of the 4 gross cranial variables (Gtl, Cbl, Biorb, Bican) via discriminant analysis (Fig. 3), the 2 species-groups separate, but not strongly, and there is a slight overlap. Inspection of the coefficients shows that the Propithecus diadema group has a lower $\mathrm{Cbl}$ relative to $\mathrm{Gtl}$, reflecting their shorter basicranium, and higher Bican relative to Biorb, reflecting the wider rostrum compared to most (but not all) of the P. verreauxi group. Notably, the separation of Propithecus coronatus from all other taxa far exceeds the separation between the traditional 2 specific groups.

\section{Canonical Discriminant Functions}

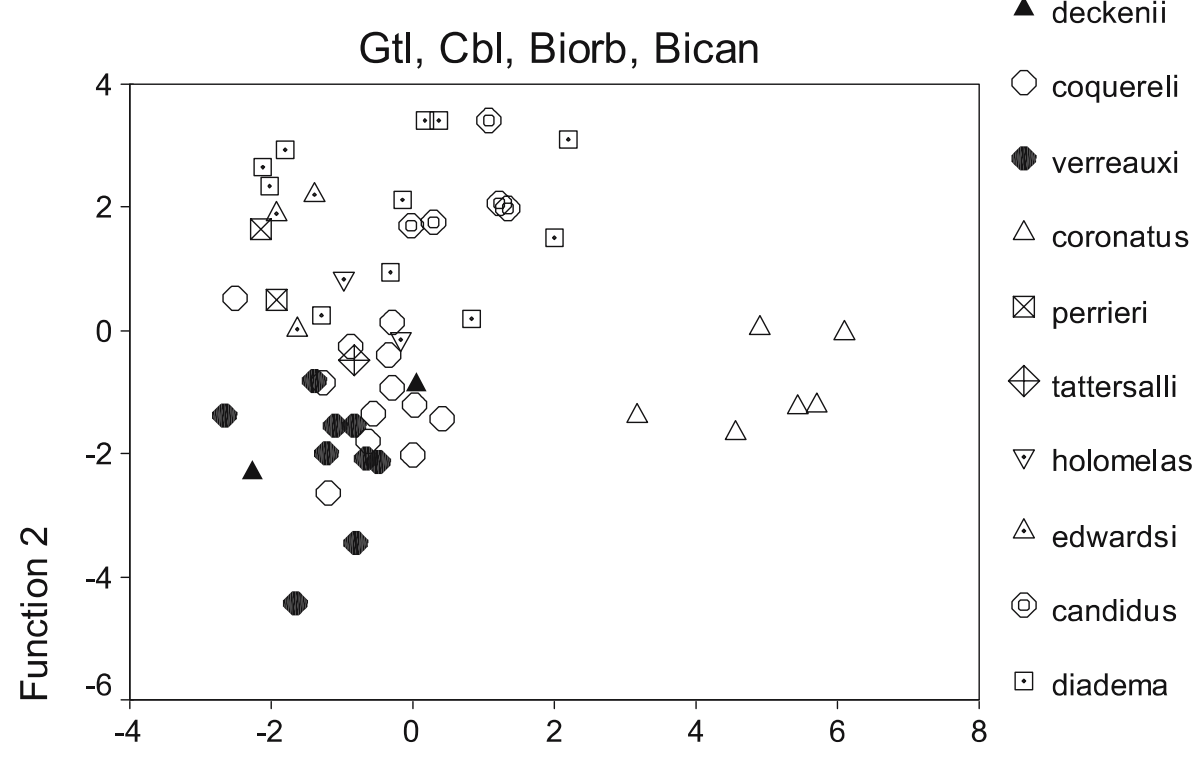

\section{Function 1}

Fig. 3 Discriminant analysis based on 4 variables (Gtl, Cbl, Biorb, Bican) for all taxa of Propithecus. The first function accounts for $59.0 \%$ of the variance, the second for $39.8 \%$. The coefficients for the raw variables are as follows:

\begin{tabular}{ccc} 
& \multicolumn{2}{c}{ Function } \\
& 1 & 2 \\
GTL & 1.473 & 1.165 \\
CBL & -0.183 & -1.291 \\
BIORB & -0.417 & 0.200 \\
& & \\
BICAN & -0.739 & 0.925
\end{tabular}


Relationships within the Propithecus diadema Group

We analyzed 6 named taxa separately in the group: Propithecus diadema diadema, P. d. candidus, $P$. d. edwardsi, $P$. d. holomelas, $P$. d. perrieri, and $P$. d. tattersalli. Though the first 5 taxa are commonly regarded as conspecific, Groves (2001) found that Propithecus diadema, P. edwardsi, and P. perrieri certainly rank as full species under the PSC, conclusions that Mayor et al. (2004) subsequently supported. We include Propithecus tattersalli out of convenience and because it has the $2 n=42$ karyotype characteristic of most members of the group (vs. $2 n=48$ in the $P$. verreauxi group); and we keep $P$. holomelas separate from $P$. edwardsi for 2 reasons: 1) because its external phenotype is quite distinct and 2) because Albrecht et al. (1990) found that skulls assigned to P. holomelas are, on average, distinctly smaller.

The interorbital region in Propithecus diadema is flat between the swollen medial portions of the supraorbital rims; in P. edwardsi the interorbital region is markedly convex, and the swellings extend and fuse across the interorbital space. The external auditory meatus is somewhat larger in Propithecus diadema. The skull of Propithecus candidus resembles that of $P$. diadema. The features are not readily amenable to quantitative analysis.

Absolute size, as represented by condylobasal length, varies dramatically within the group (Fig. 4). Propithecus diadema and P. edwardsi are the largest (though the latter is represented by only 1 adult skull in this variable), followed by $P$. candidus; P. holomelas and P. perrieri are smaller, and P. tattersalli is very small.

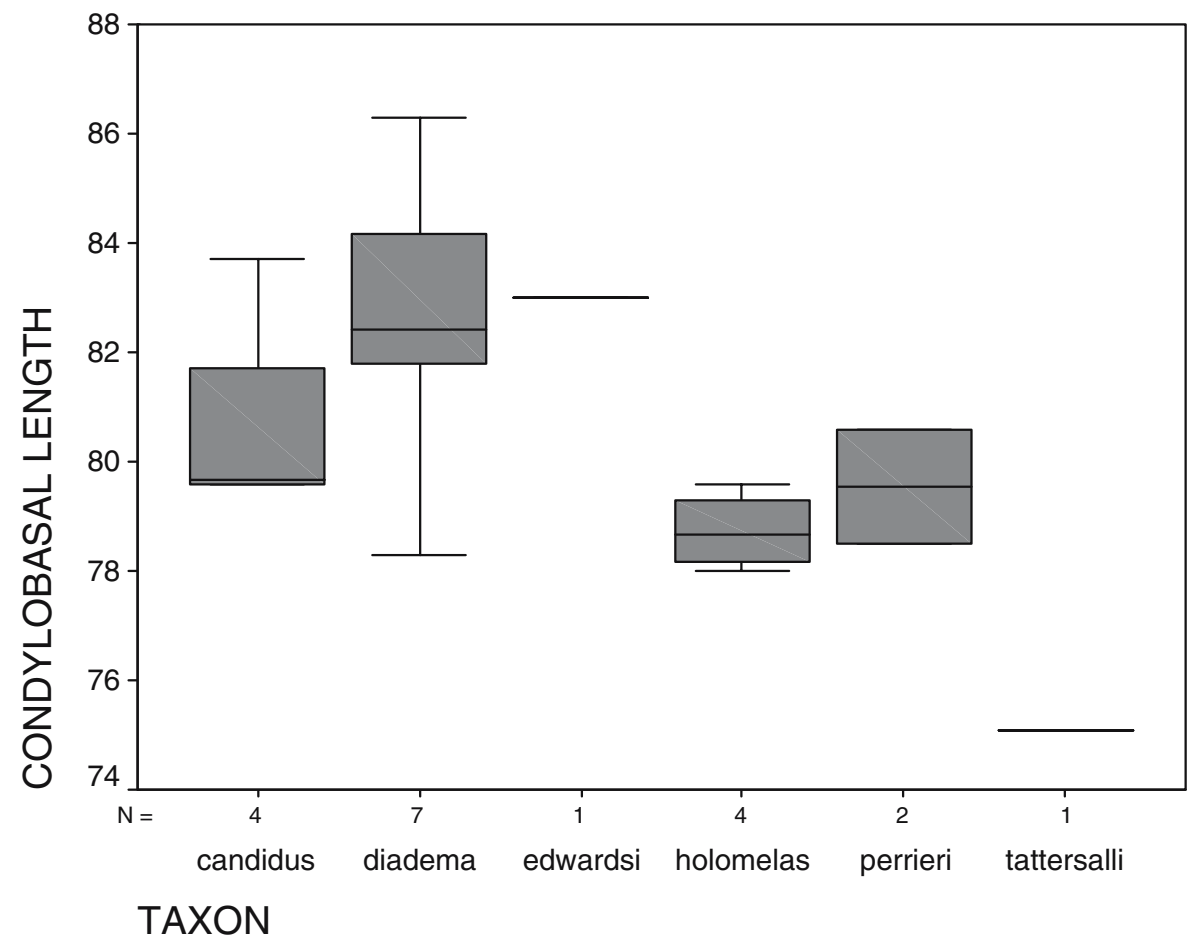

Fig. 4 Condylobasal length in the Propithecus diadema group.

Springer 
The dental proportions of Propithecus perrieri are different from those of other members of the group. $\mathrm{P}_{4}$ is relatively long compared to the mandibular toothrow (Fig. 5). Propithecus candidus has relatively long molars versus the length of the total toothrow, and taxa of the group are graded as to size (Fig. 6a), decreasing in the sequence $P$. diadema, $P$. candidus, $P$. edwardsi, $P$. holomelas/perrieri (but 1 specimen of $P$. holomelas is unusually large, in the range of Propithecus diadema); members of the Propithecus verreauxi group are not graded in this way, only $P$. deckenii and $P$. coquereli being somewhat larger than the rest, and overlapping with the smallest members of the $P$. diadema group (Fig. 6b).

\section{Relationships within the Propithecus verreauxi Group}

In what follows, we separately analyzed all 4 taxa: Propithecus verreauxi, $P$. deckenii, P. coronatus, and P. coquereli. Visually, Propithecus coquereli differs from the other 3 in its shallow snout, which drops down sharply from the swollen interorbital region; in the others, the interorbital pillar slopes down to the rostrum with only a slight drop. In Propithecus coronatus the snout is not only deepened but also extremely broad and inflated at and behind the canine roots; in $P$. verreauxi and $P$. coquereli the snout is narrow; $P$. deckenii is intermediate, somewhat raised and broad but not inflated, so that the rostrum is straight-sided. The entire facial skeleton is broadened and deepened in Propithecus coronatus. The braincase is high and rounded in Propithecus verreauxi, low and flat in the other 3. We have devised

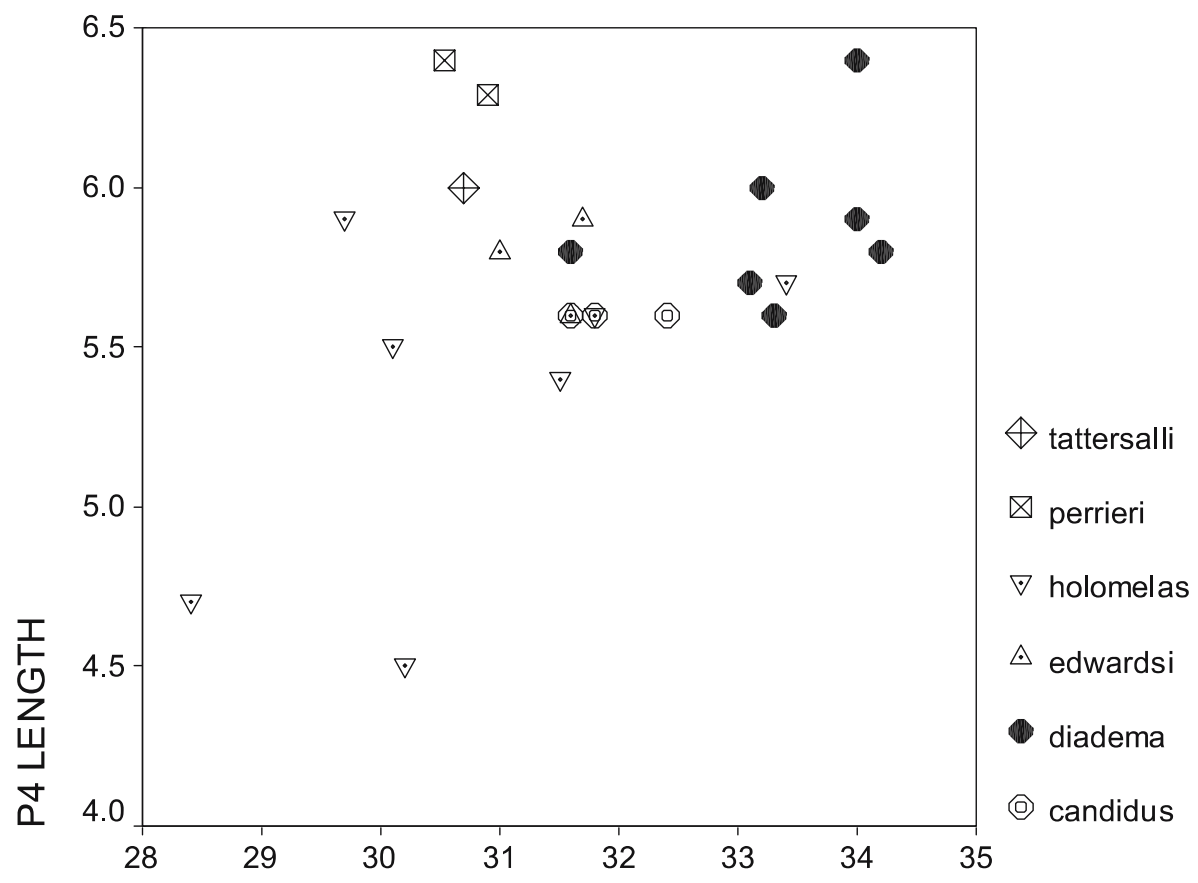

\section{MANDIBULAR TOOTHROW}

Fig. $5 \mathrm{P}_{4}$ length compared to mandibular toothrow length in the Propithecus diadema group. 

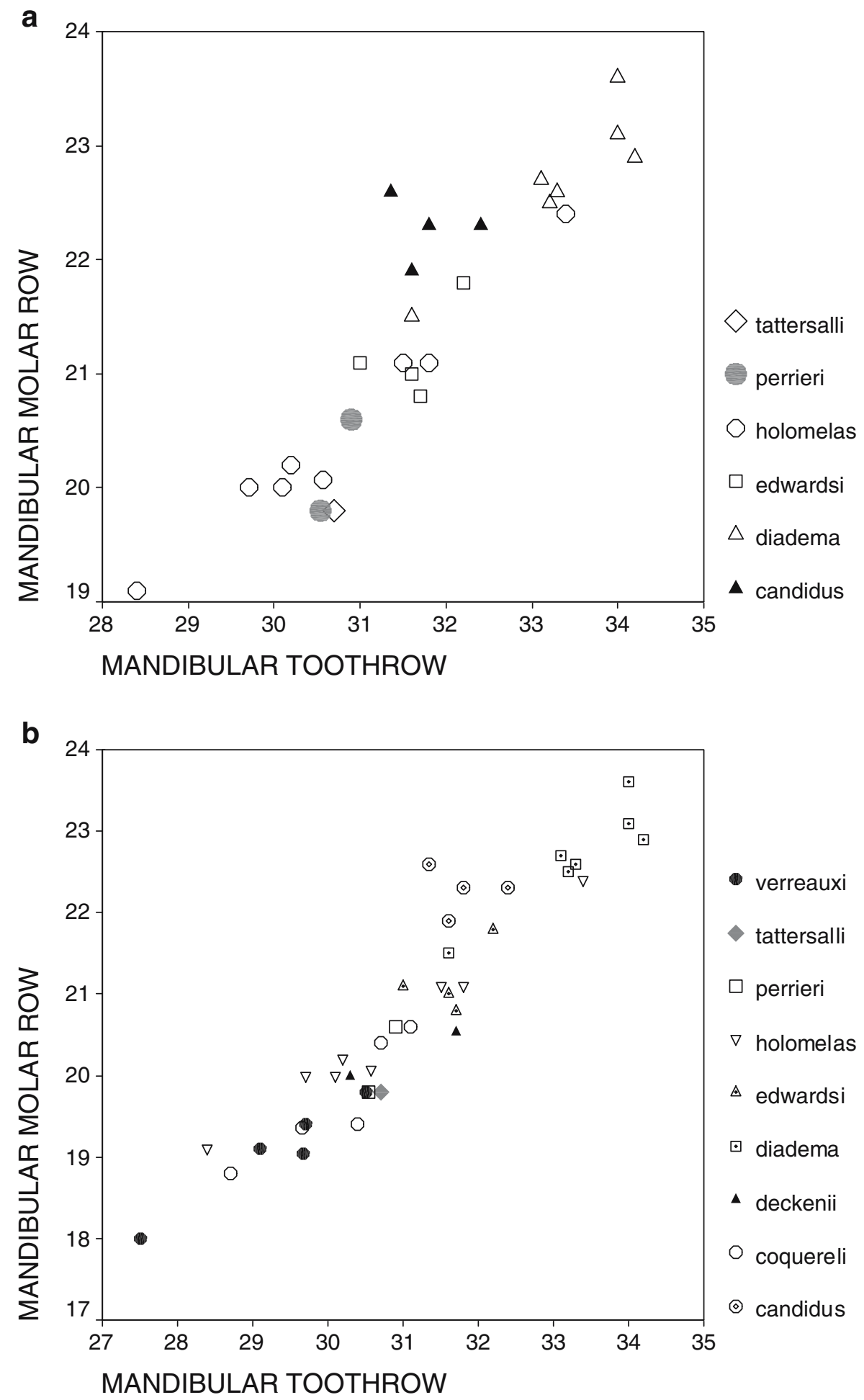
4 Fig. 6 Mandibular molar row compared to total toothrow length in (a) the Propithecus diadema group and (b) genus Propithecus.

methods to analyze the features quantitatively. In addition, the nuchal crest tends to be strong medially but weakly developed laterally in Propithecus coronatus, uniformly strong or even emphasized laterally in $P$. coquereli and especially $P$. deckenii, usually uniformly weak in $P$. verreauxi.

We compare absolute sizes, as represented by condylobasal length, in the 4 taxa in Fig. 7. Sample sizes, except for Propithecus coquereli, are small; on present evidence, $P$. verreauxi would seem to average slightly smaller than the other 3 taxa.

We illustrate the extraordinary rostral inflation of Propithecus coronatus in Fig. 8. The snouts of other taxa are much narrower; it varies widely in Propithecus deckenii, and a few individuals approach that of $P$. coronatus, but do not overlap.

Biorbital breadth in Propithecus coronatus is relatively broader than in the other 3 (Fig. 9), and that of $P$. deckenii does not approach it.

Cranial deepening is illustrated in Fig. 10; not only Propithecus coronatus but also $P$. coquereli also have high skulls, despite the broadening in the former. The relatively deep rostra of Propithecus coronatus and $P$. deckenii are illustrated in Fig. 11.

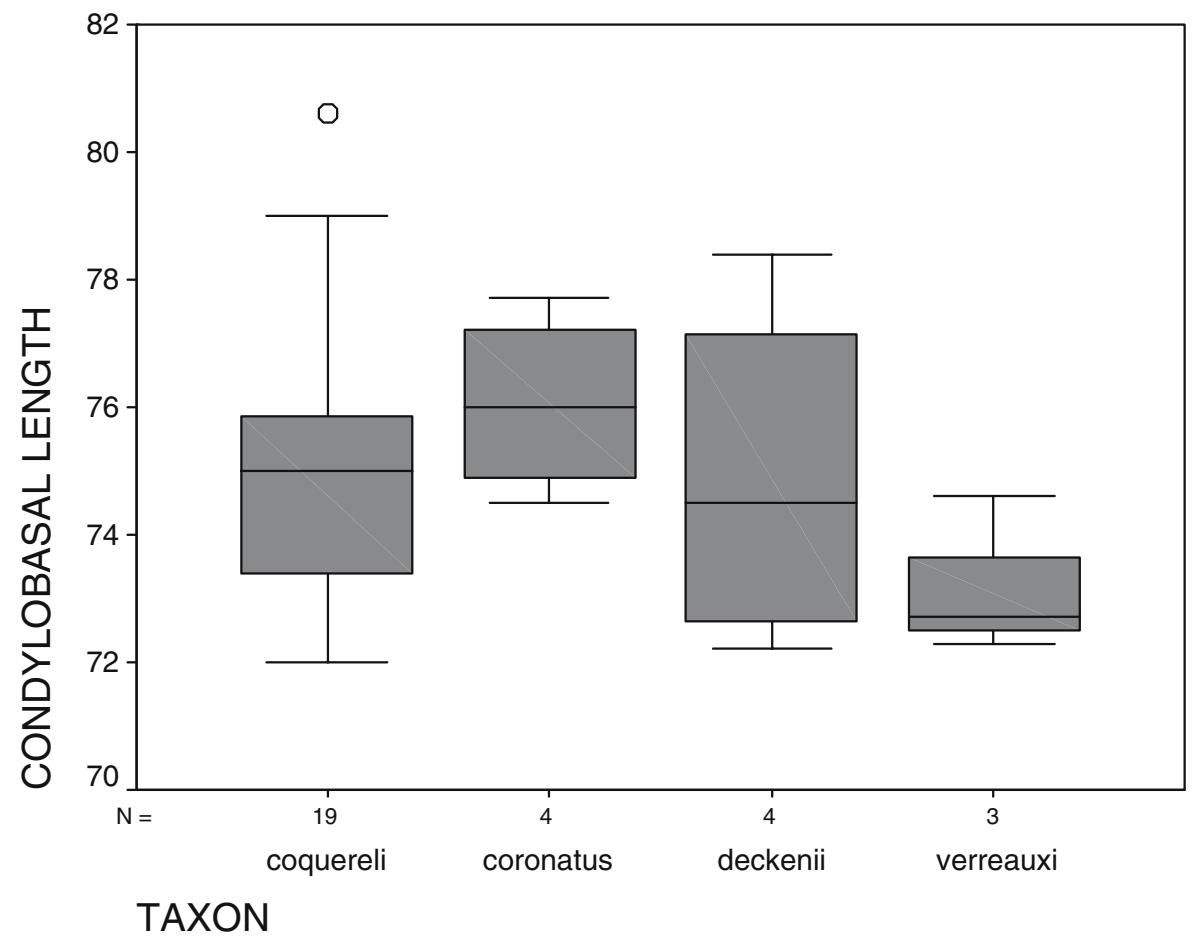

Fig. 7 Condylobasal length in the Propithecus verreauxi group. 


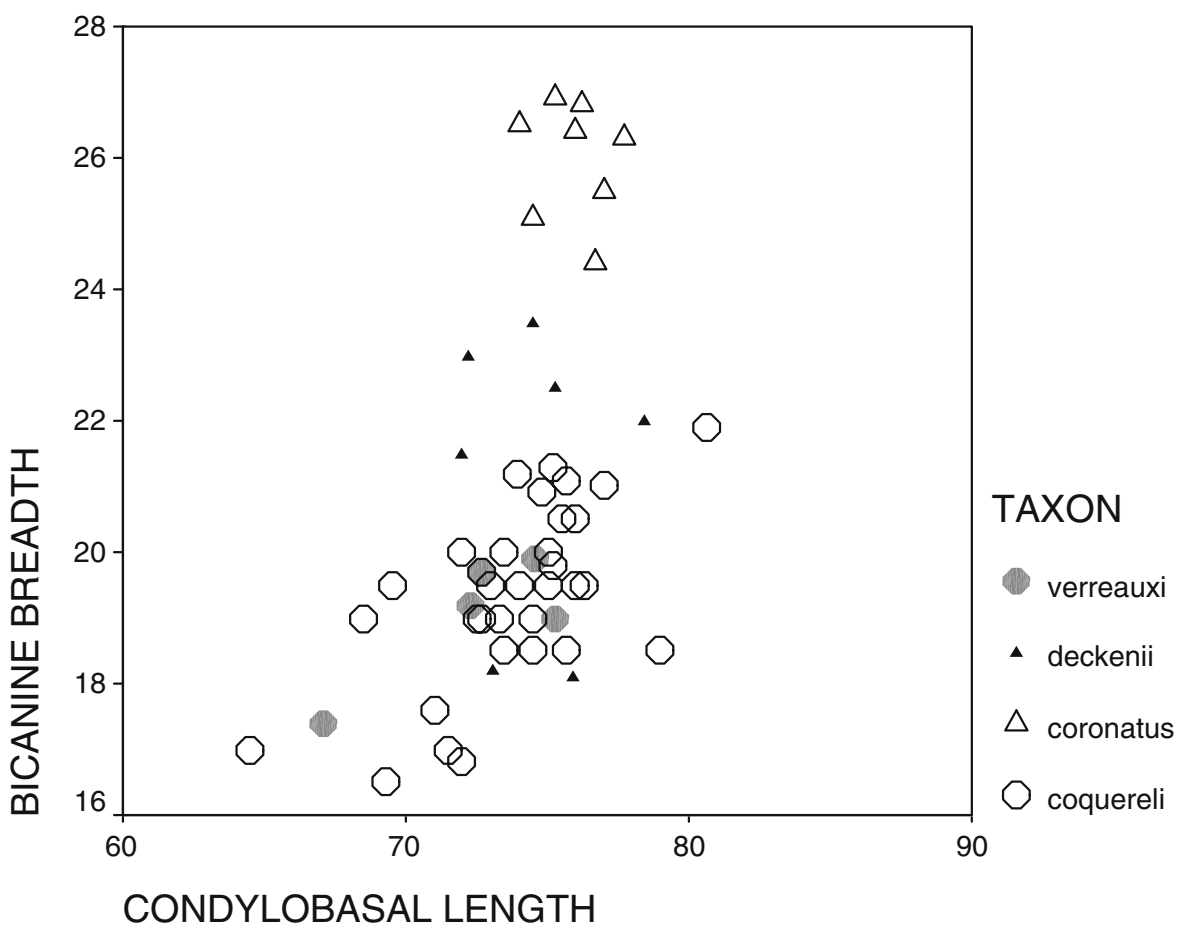

Fig. 8 Bicanine breadth compared to condylobasal length in the Propithecus verreauxi group.

Relative tooth size is depicted in Fig. 12. The maxillary toothrow of Propithecus verreauxi is somewhat longer, versus condylobasal length, than in the others.

A discriminant analysis based on 6 cranial variables (Fig. 13) contrasts Propithecus coronatus with the other taxa of the group; it is well separated on the first function (depending mainly on high bicanine breadth compared to skull size and braincase height), and the single available specimen of $P$. deckenii approaches it only slightly. On the second function, Propithecus verreauxi is slightly separated from $P$. coquereli, indicating that it has a greater biorbital width and lower braincase and interorbital heights.

\section{Discussion}

Our results shed further light on the taxonomy and evolution of Propithecus. It is very noticeable that the cranial differences between the 2 traditional species-groups as a whole are less than those within 1 of them: the $P$. verreauxi group. This is consistent with the recent molecular findings of Mayor et al. (2004), which suggest that the "Propithecus verreauxi group" (including P. tattersalli) is not monophyletic, but instead is a succession of taxa basal to a monophyletic $P$. diadema group, concordant with much less comprehensive phylogenetic results reported by Pastorini 


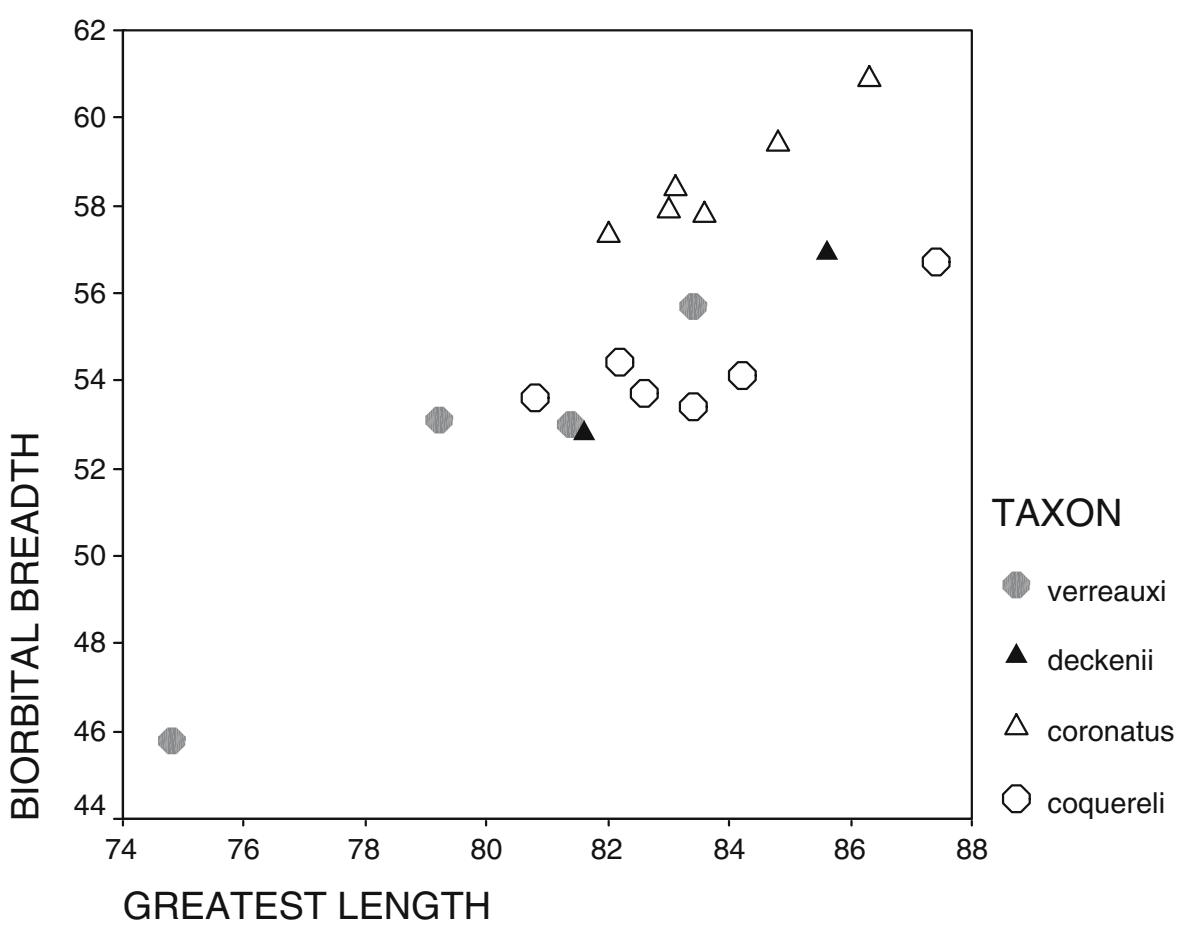

Fig. 9 Biorbital breadth compared to condylobasal length in the Propithecus verreauxi group.

et al. (2001) and Rumpler et al. (2004). Larger average body size, reduced auditory bullae, and a distinctively rounded mandibular condyle appear to be synapomorphous ecomorphological features that unite the closely related species of the Propithecus diadema group. Importantly, Propithecus tattersalli lacks these features, and despite its karyotype, can be conclusively removed from the $P$. diadema group, where has often the placed (Groves, 2001; Tattersall, 1982).

Within each of the traditional species-groups there are some additional findings. First is the elongated $\mathrm{P}_{4}$ of Propithecus perrieri. While Propithecus perrieri has the karyotype $(2 n=42)$ typical of $P$. diadema and $P$. candidus, it otherwise differs markedly from these taxa. It has never been clear to us why it was reduced to the status of a subspecies of Propithecus diadema in the first place; the classification has seemed especially anomalous since the discovery of $P$. tattersalli, whose range intervenes between that of $P$. perrieri and the rest of the $P$. diadema group.

Groves (2001) and Mayor et al. (2004) recognized Propithecus edwardsi (with unique karyotype $2 n=44$ ) as a distinct species and we maintain the status here. It is craniometrically, externally, genetically, and karyotypically distinctive, and its specific status is potentially bolstered even further by rumors of its sympatric occurrence with Propithecus diadema in some areas (Mayor et al. 2004).

The status of Propithecus cf. diadema candidus required reexamination. Groves (2001) retained it as a subspecies of Propithecus diadema because coloration in some specimens appeared to vary in the direction of true P. diadema (Petter et al. 


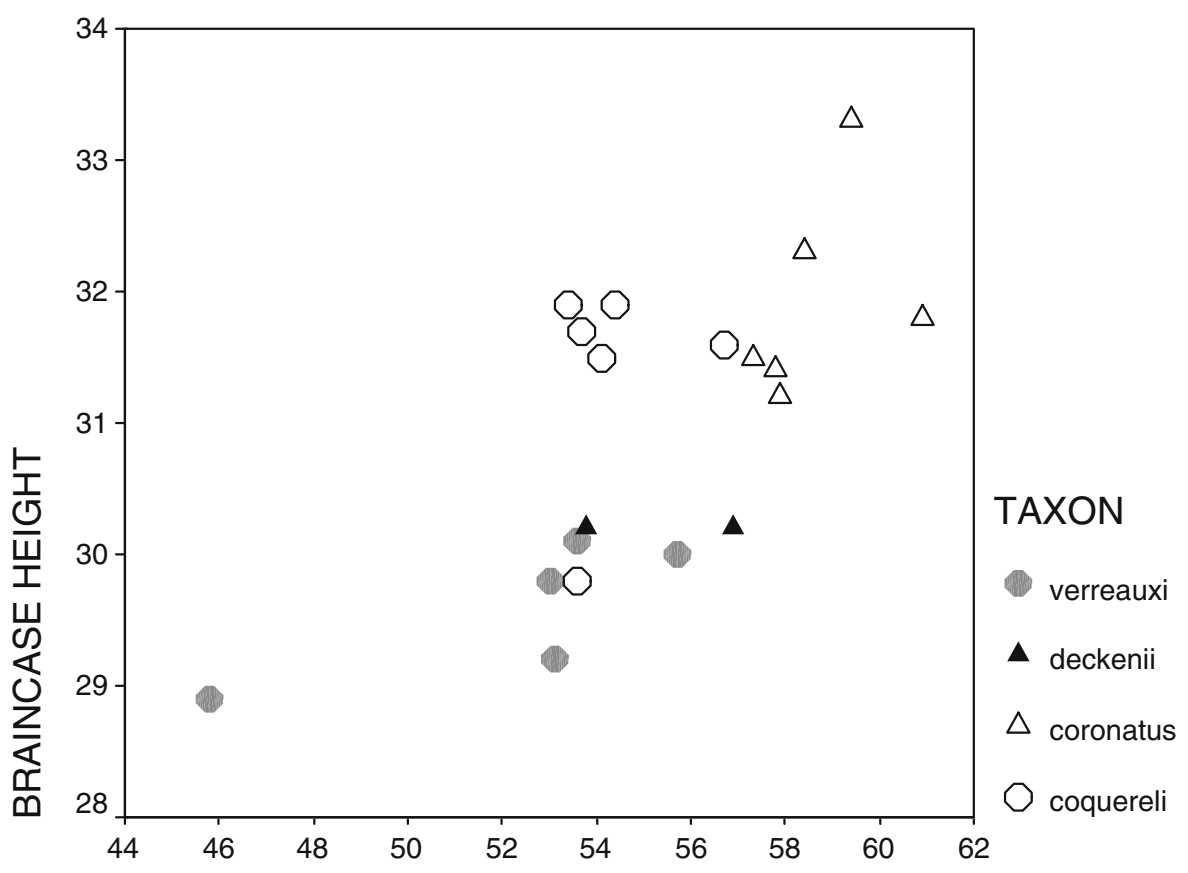

\section{BIORBITAL BREADTH}

Fig. 10 Braincase height compared to biorbital breadth in the Propithecus verreauxi group.

1977). Still, there remains a gap in pelage pattern between them, and we found some craniometric differences between them, though they are not great and may not be consistent. The findings of Mayor et al. (2004), however, are unequivocal: judging from D-loop sequences Propithecus candidus comprises a monophyletic lineage quite separate from that of $P$. diadema. Further, the morphometric studies of Mayor et al. (2004) showed that they have distinctive external proportions, being largerbodied than Propithecus diadema but with a shorter tail, and nonmetric cranial features also appear to distinguish the 2 taxa. It is clear that we should recognize Propithecus candidus as a full species.

The most surprising result in the Propithecus diadema group concerns the taxon holomelas. The admittedly small sample available to us, all from Andalusa or Fienerentova, differs strongly in its small size from the single available adult skull of Propithecus edwardsi, which is from Mananzari (Albrecht et al. 1990), though it overlaps with $P$. diadema. In light of Tattersall's (1986) discovery that individuals externally assignable to both taxa occur at the same locality (map, Fig. 1, in Tattersall, 1986), there are 2 possibilities: that the cranial and external differences are consilient, and that they constitute 2 marginally sympatric species; or that a single species, locally polymorphic in pelage characters, varies geographically in size. Provisionally, we regard Propithecus holomelas as a full species, in part to draw attention to its conservation status, but more research is certainly needed, including both studies 


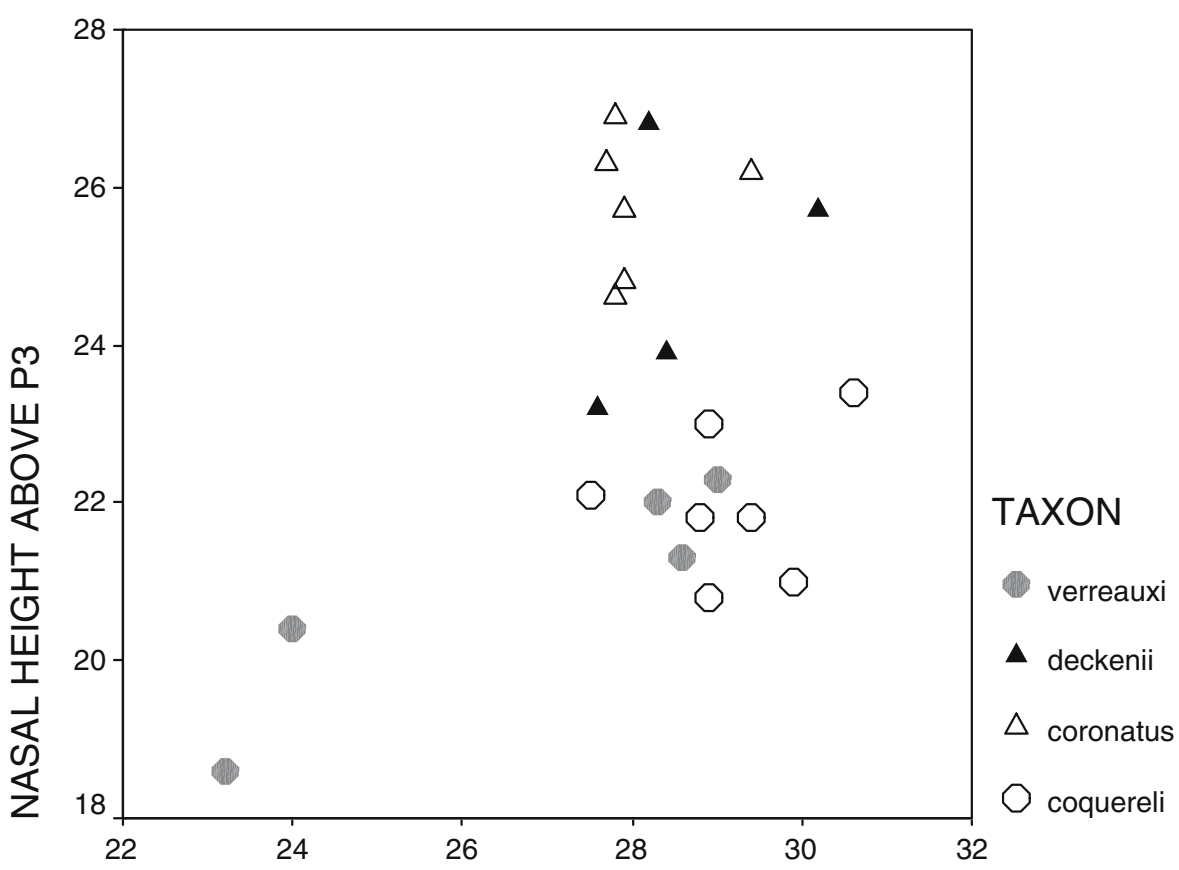

INTERORBITAL HEIGHT

Fig. 11 Nasal height compared to interorbital height in the Propithecus verreauxi group.

drawing from D-loop sequences and more comprehensive morphological comparisons of material currently assigned to holomelas and edwardsi in world museums.

In the "Propithecus verreauxi group" all 4 traditionally recognized subspecies are distinct cranially, and skull characters confirm not only the validity of the 3 species that Groves (2001) recognized (P. verreauxi, P. coquereli, and P. deckenii) but also the specific status of $P$. coronatus, as Thalmann et al. (2002) recently argued; in fact the last species is the most distinct of all in its cranial characters. In the group, there is a clear centrifugal pattern in cranial characters: peripheral Propithecus verreauxi (southern) and $P$. coquereli (northern) are cranially primitive (though not identical to each other), and central $P$. coronatus is highly derived; $P$. deckenii, geographically intermediate between $P$. verreauxi and $P$. coronatus, is cranially intermediate between them though much closer to $P$. verreauxi (not to $P$. coronatus as usually reported; Petter et al. 1977). Notably, the craniometric evidence thereby fills in the principal gap in the study of Mayor et al. (2004), which did not incorporate either Propithecus deckenii or P. coronatus. We can conclusively transfer Propithecus tattersalli out of the $P$. diadema group, though strictly speaking there is no $P$. verreauxi "group" to transfer it into because, in contrast to the group of $P$. diadema, it seems to comprise a grade rather than a clade.

We leave for a future study the question of whether the genus Propithecus is itself monophyletic with respect to either or both of the 2 other genera of the Indriidae, in particular Indri. 


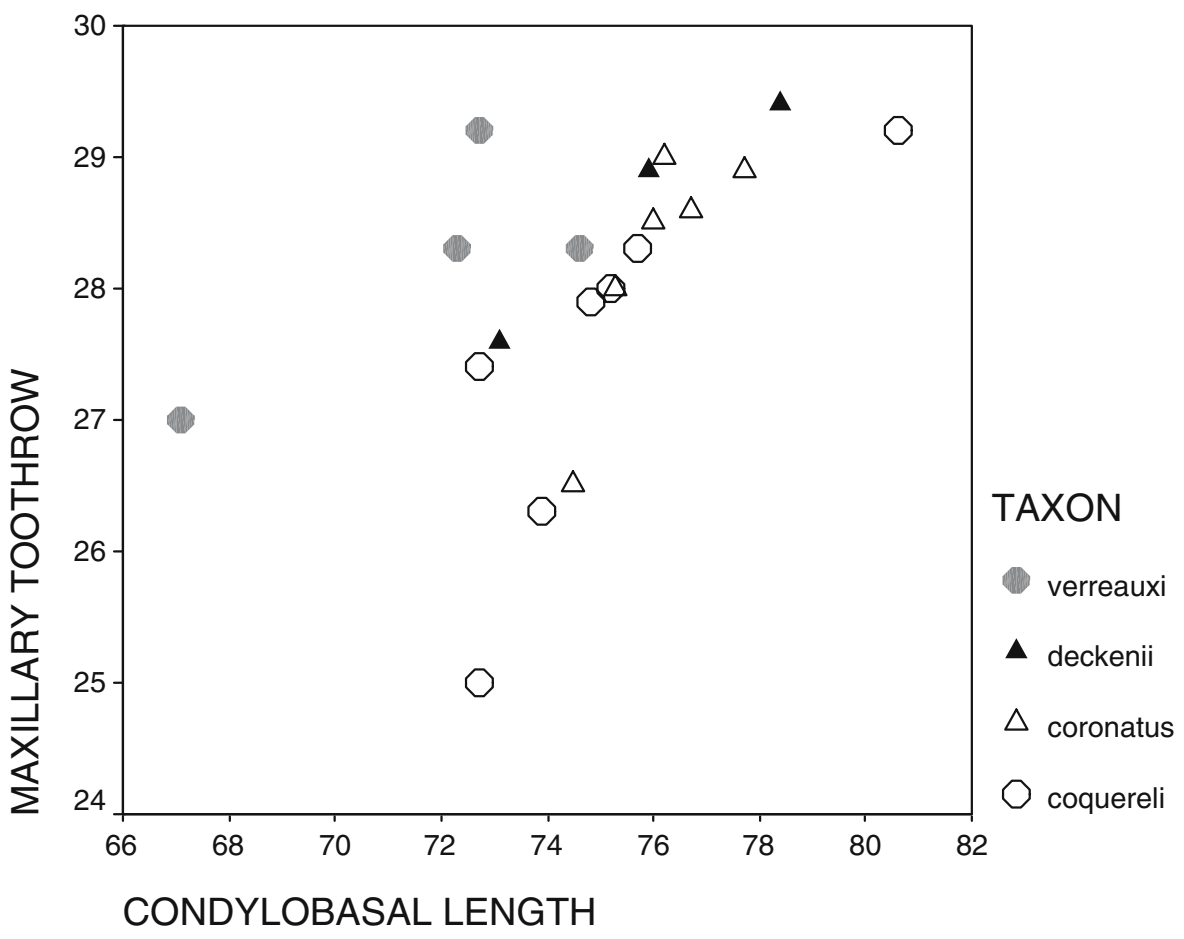

Fig. 12 Maxillary toothrow length versus condylobasal length in the Propithecus verreauxi group.

\section{Conclusions}

Craniodental measurements add to other data in corroborating and extending the classification of Propithecus (see Table I at Appendix), resulting in our recognition of 9 or 10 species of sifakas (under PSC criteria), as follows:

Propithecus Bennett, 1832

$P$. diadema group

1. P. diadema Bennett, 1832

2. P. edwardsi Grandidier, 1871

3. ? P. holomelas Günther, 1875 (perhaps a morph of $P$. edwardsi)

4. P. candidus Grandidier, 1871

5. P. perrieri Lavauden, 1931

P. "verreauxi group"

6. P. coquereli (Grandidier, 1867)

7. $P$. verreauxi Grandidier, 1867

8. P. deckenii Peters, 1870

9. P. coronatus Milne-Edwards, 1871

10. P. tattersalli Simons, 1988

를 Springer 
Canonical Discriminant Functions

P.verreauxi group

Cbl, Biorb, Bican, Brainht, Inht, Nasht

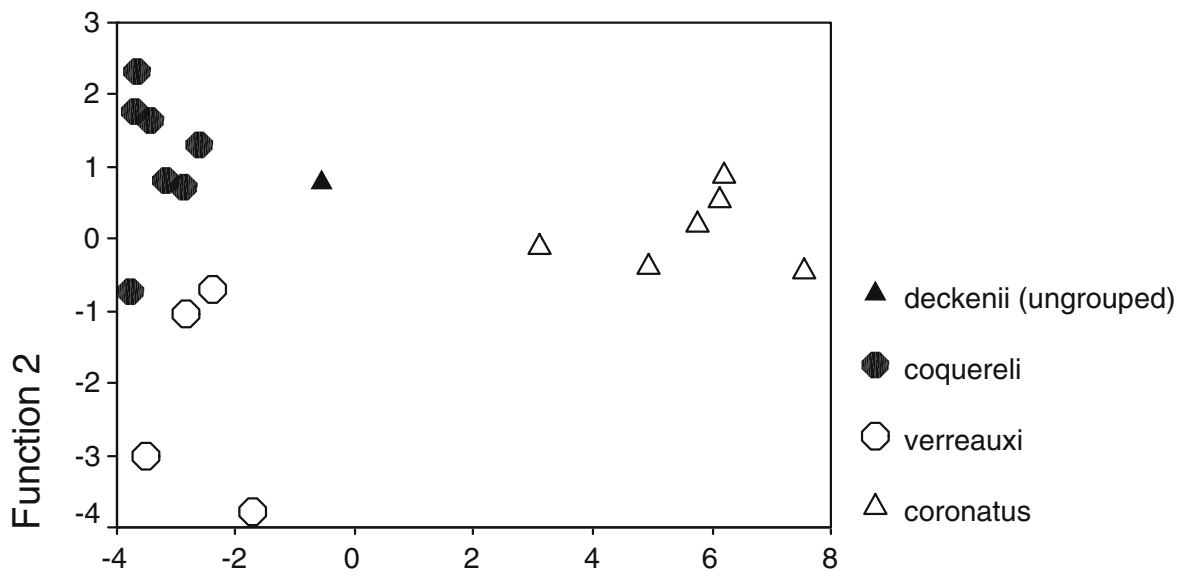

Function 1

Fig. 13 Discriminant analysis based on 6 variables (Cbl, Biorb, Bican, Brainht, Inht, Nasht) for the Propithecus verreauxi group. DF1 accounts for $91.6 \%$ of the total variance, DF2 for $8.4 \%$. The coefficients for the raw variables are as follows.

\begin{tabular}{ccc} 
& \multicolumn{2}{c}{ Function } \\
& 1 & 2 \\
CBL & -0.999 & 0.482 \\
BIORB & 0.379 & -0.817 \\
BICAN & 1.654 & -0.052 \\
BRAINHT & -0.804 & 0.725 \\
INHT & -0.326 & 0.762 \\
NASHT & 0.208 & 0.144
\end{tabular}

Cranially, the most distinctive of the latter species are Propithecus coronatus and P. tattersalli.

Groves (2001) delineated taxonomic synonyms and geographic ranges of each taxon.

Acknowledgments We thank Chris Smeenk (RMNH), Paula Jenkins, Richard Harbord, and Daphne Hills (BMNH), Judy Chupasko (MCZ), Darrin Lunde (AMNH), Peter Giere and Irene Thomas (ZMB), and Bill Stanley (FMNH) for access to museum specimens and other assistance. Judy Chupasko and Darrin Lunde took some extra measurements for us. Grants from the South Australian Museum and the Smithsonian Institution supported C. M. Helgen's museum research abroad. 


\section{Appendix}

Table I Skulls of Propithecus spp. studied

Not all of the skulls are complete and offer the full set of measurements.

\begin{tabular}{|c|c|c|c|c|c|}
\hline & \multirow[t]{2}{*}{ Total } & \multicolumn{3}{|l|}{ Adult } & \multirow[t]{2}{*}{ Subadult } \\
\hline & & Male & Female & Sex? & \\
\hline P. diadema & 12 & 4 & 3 & 1 & 4 \\
\hline P. candidus & 5 & 2 & 3 & - & - \\
\hline P. edwardsi & 4 & 1 & 1 & 1 & 2 \\
\hline P.holomelas & 8 & 5 & 1 & - & 2 \\
\hline P. tattersalli & 1 & 1 & - & - & - \\
\hline P. perrieri & 2 & 1 & 1 & - & - \\
\hline P. coronatus & 8 & 3 & 1 & - & 4 \\
\hline P. coquereli & 38 & 11 & 12 & - & 15 \\
\hline P. verreauxi & 11 & 4 & 3 & 2 & 2 \\
\hline P. deckeni & 10 & 2 & 2 & 2 & 4 \\
\hline
\end{tabular}

\section{References}

Albrecht, G. H., Jenkins, P. D., \& Godfrey, L. R. (1990). Ecogeographic size variation among the living and subfossil prosimians of Madagascar. American Journal of Primatology, 22, 1-50.

Allen, G. M. (1939). A checklist of African mammals. Bulletin of the Museum of Comparative Zoology of Harvard, 83, 1-763.

Anon (1999). Where art thou, Juliet? Science, 286, 897.

Curtis, D. J., Velo, A., Raheliarisoa, E.-O., Zaramody, A., \& Müller, P. (1998). Surveys on Propithecus verreauxi deckeni, a melanistic variant, and P. v. coronatus in north-west Madagascar. Oryx, 32, 157-164.

Davis, J. I., \& Nixon, K. C. (1992). Populations, genetic variation, and the delimitation of phylogenetic species. Systematic Biology, 41, 421-435.

Garbutt, N. (1999). Mammals of Madagascar. Sussex, U.K.: Pice Press.

Groves, C. P. (2001). Primate Taxonomy. Washington, D.C.: Smithsonian Institution Press.

Helgen, K. M. (2002). Guillaume Grandidier's mammal collections from Madagascar. Mammalian Biology, 67, 381-383.

Hill, W. C. O. (1953). Primates. Comparative Anatomy and Taxonomy. 1. Strepsirhini. Edingurgh : Edinburgh University Press.

Kaudern, W. (1915). Säugetiere aus Madagaskar. Arkiv für Zoologi, 9(18), 1-101.

Lavauden, L. (1931). Un nouveau Propithèque de Madagascar (Propithecus perrieri, sp. nov.). Comptes Rendus Hebdomadaires des Seances de l'Academie des Sciences, 193, 77-79.

Mayor, M. I., Sommer, J. A., Houck, M. L., Zaonarivelo, J. R., Wright, P. C., Ingram, C., et al. (2004). Specific status of Propithecus spp. International Journal of Primatology, 25, 875-900.

Pastorini, J., Forstner, M. R. J., \& Martin, R. D. (2001). Phylogenetic history of sifakas (Propithecus: Lemuriformes) derived from mtDNA sequences. American Journal of Primatology, 53, 1-17.

Petter, J-J., Albignac, R., \& Rumpler, Y. (1977). Faune de Madagascar. 44. Mammifères Lémuriens (Primates Prosimiens). Paris : ORSTOM/CNRS.

Poorman, P. A. (1983). The banded chromosomes of Coquerel's sifaka, Propithecus verreauxi coquereli (Primates, Indriidae). International Journal of Primatology, 4, 419-425.

Rumpler, Y., \& Albignac, R. (1979). Cytogenetic study of the Indridae Bennett, 1832, an endemic Malagasy lemur family. In Comparative Karyology of Primates (pp. 29-34). The Hague: Mouton.

Rumpler, Y., Andriaholinirina, N., Warter, S., Hauwy, M., \& Rabarivola, C. (2004). Phylogenetic history of the Sifakas (Propithecus: Lemuriformes) derived from cytogenetic studies. Chromosome Research, 12, 453-463.

Rumpler, Y., \& Andriamiandra, A. (1971). Etude histologique des glandes de marquage de la face antérieure du cou des Lémuriens malgaches. Comptes Rendus des Seances de la Societe de Biologie et de ses Filiales, 165, 436-440. 
Rumpler, Y., Warter, S., Ishak, B., \& Dutrillaux, B. (1988). Chromosome evolution in Malagasy lemurs. X. Chromsomal banding studies of Propithecus diadema edwardsi and Indri indri and phylogenetic relationships between all the species of the Indriidae. American Journal of Primatology, 16, 63-71.

Schlegel, H. (1876). Les faux-singes. Prosimiae. Muséum d'Histoire Naturelle des Pays-Bas, 12, $279-337$.

Schwarz, E. (1931). A revision of the genera and species of Madagascar Lemuridae. Proceedings of the Zoological Society of London, 1931, 399-426.

Simons, E. L. (1988). A new species of Propithecus (Primates) from Northeast Madagascar. Folia Primatologica, 50, 143-151.

Tattersall, I. (1982). The Primates of Madagascar. New York: Columbia University Press.

Tattersall, I. (1986). Notes on the distribution and taxonomic status of some subspecies of Propithecus in Madagascar. Folia Primatologica, 46, 51-63.

Thalmann, U., Kümmerli, R., \& Zaramody, A. (2002). Why Propithecus verreauxi deckeni and $P$. $v$. coronatus are valid taxa - quantitative and qualitative arguments. Lemur News, 7, 11-16. 